\section{Managing the phase-down of amalgam: part I. Educational and training issues}

\author{
C. D. Lynch*1 and N. H. F. Wilson²
}

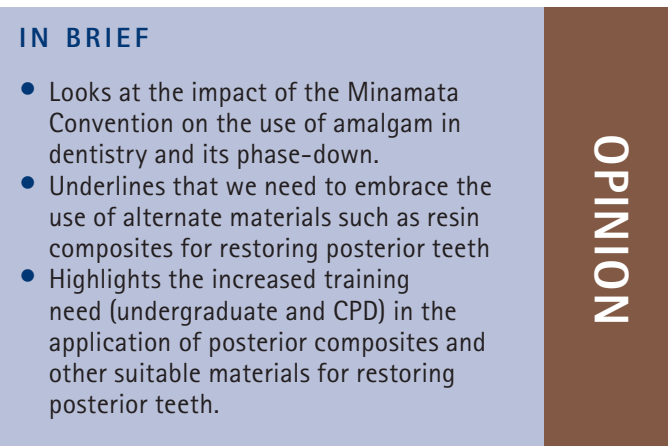

\begin{abstract}
Following the recently agreed Minamata Convention, a phase-down in the use of dental amalgam will become a priority for the profession. With a lead-in period of a number of years, important changes in the mind-set of the profession are required to ensure that patient safety is not compromised. Posterior composites have been a viable, and in many cases preferable, alternative to amalgam for many years. However, notwithstanding considerable developments in dental school teaching on the application and placement of posterior composites, growing evidence to support the use of composites in the restoration of posterior teeth and advances in composite systems, many practitioners remain reluctant to place composite rather than amalgam. This paper considers the present and future use of posterior composites and highlights ways in which dental school teaching and continuing professional development (CPD) may contribute to the successful phasedown, and now inevitable discontinuation, in the use of dental amalgam.
\end{abstract}

\section{INTRODUCTION}

The recently-agreed Minamata Convention heralding a world-wide reduction and ultimate cessation in the production and use of mercury containing products will irrevocably change the practice of dentistry in the coming years. ${ }^{1,2}$ It is noted that the Convention agrees a ban on the production, export and import of a range of mercury-containing products such as batteries, switches and relays, certain types of compact fluorescent lamps, mercury in cold cathode fluorescent lamps and external electrode fluorescent lamps, as well as mercury in soaps and cosmetics by $2020 .{ }^{1}$ Furthermore delegates agreed 'a phase-down in the use of dental fillings using mercury amalgam.' Notwithstanding this apparent reprieve for amalgam, the likely direction in the use and availability of mercury containing products, including dental amalgam, is obvious.

\footnotetext{
Reader/Honorary Consultant in Restorative Dentistry, School of Dentistry, Cardiff University, Cardiff;

${ }^{2}$ Professor of Dentistry, King's College London Dental Institute, London

${ }^{*}$ Correspondence to: Dr Christopher D. Lynch

Email: lynchcd@cardiff.ac.uk
}

Accepted 9 May 2013

DOI: 10.1038/sj.bdj.2013.737

${ }^{\circledR}$ British Dental Journal 2013; 215: 109-113
For more than 150 years dental amalgam was, and in many countries continues to be, the mainstay of operative dentistry treatments. This has especially been the case in the United Kingdom where the use of dental amalgam has historically underpinned large elements of NHS dental care. ${ }^{3,4}$ One of the consequences of this approach, which served great purpose for many years, is the "heavy-metal generation' phenomenon. ${ }^{5}$ This is a large number of ageing dentate patients who previously received many and extensive amalgam restorations, and who now have to live with the legacy of weakened teeth restored with what are increasingly viewed as unaesthetic, mechanically retained, metallic inserts. The design of most of the restorations in clinical service in 'heavy metal generation' patients is based on now outdated mechanistic approaches to operative dentistry developed by founding fathers of twentieth century dentistry, notably G. V. Black. Many of us will recall from our dental school days being taught to create 'ideal' cavity forms with occlusal 'dovetails', wide isthmuses, flat floors, flared boxes, sharply defined line and point angles and all-important undercuts, not to forget 'extension for prevention'. Significantly these features and principles of cavity preparation had more to do with the requirements of the restorative material, typically dental amalgam, rather than the extent of caries or other damage to tooth tissues. Dental amalgam, if placed according to time-honoured principles and with due care and attention to detail, performs well in clinical service, notably in terms of the restoration of form and function. However, there comes a time, as is well known to "heavy metal generation' patients, when the failure of a large dental amalgam leaves no option other than extraction or advanced, often complex and costly forms of care. Examples of these include extracoronal restorations with or without endodontic treatment, with all the associated costs and, in turn, further consequences and sequelae of the mechanistic, 'excisional' approach to the treatment of disease. Even G. V. Black recognised the disadvantages of the approach he promoted when he famously stated in the 1890s that 'the time is surely coming when we will be practicing preventive rather than reparative dentistry.

Given recurring concerns over possible adverse health effects of dental amalgam, the authors feel it necessary to emphasise that they share the view held by various national and international dental organisations that the use of dental amalgam is safe. Also, the authors feel it necessary to 
clarify that they are not 'anti-amalgam' However, in common with many professional colleagues, they consider themselves to be proponents of minimally interventive, conservative dentistry that relies on the successful placement of posterior composites and restorations of other tooth-coloured restorative systems, rather than amalgam.

\section{ALTERNATIVES NOT SUBSTITUTES}

For many years the evidence-base and demand for the use of tooth-coloured systems in the restoration of posterior teeth has been growing. ${ }^{6-8}$ Fundamental to the increasing use of tooth-coloured restorative systems in the restoration of posterior teeth is the realisation that these systems must be applied and placed by alternative means and according to different principles. ${ }^{9}$ If a tooth-coloured restorative material is viewed and used/handled as 'white amalgam', the clinical outcomes and performance will be poor. ${ }^{10,11}$ Posterior composites, when applied and placed in ways that favour the clinical performance of resin composites, offer many important advantages over amalgam restorations, which they have been shown capable of matching in terms of longevity. ${ }^{6-8}$ These advantages include:

- The opportunity to be conservative of tooth tissue and to apply modern approaches to the management of dentine caries ${ }^{10}$

- Adhesion and bonding to remaining tooth tissues, with the prospect of marginal seal ${ }^{11}$

- Ability to incorporate preventive measures including sealing of adjacent pits and fissures ${ }^{12}$

- Strengthening and enhanced biomechanical properties of the restored tooth unit $^{13}$

- Good aesthetic appearance and high patient acceptance

- Ease of subsequent refurbishment and repair. ${ }^{14-20}$

Well established in the highly successful restoration of anterior teeth, it is through the capacity to conserve, adhere to, and mimic tooth tissues that the true benefits of composite systems become apparent. When placing a composite restoration it is sufficient to remove irretrievably damaged and infected dentine, carefully finish the margins and restore the resultant cavity. There is no need to extend the cavity at the expense of the precious resource of sound tooth tissue, let alone incorporate 'retentive features', which greatly add to the weakening effects of cavity preparation. ${ }^{10}$ In making the paradigm shift from a 'mechanically-driven' to a 'biologically-focused' approach to the restoration of posterior teeth, it is necessary to transition into adapting and applying approaches found to be successful in the restoration of anterior teeth to the restoration of posterior teeth. It has previously been suggested that, in particular for those practising traditional operative dentistry, learning to successfully use composite rather than amalgam in the restoration of posterior teeth is similar to learning a new language: you are competent once you become confident, fluent, think, and can effectively communicate in the new language. To use composite systems to their best possible advantage clinicians must be fully conversant with all the relevant science and artistry and be able to adapt and apply their knowledge, skill and understanding effectively in the many different situations encountered in clinical practice. All that said, it is acknowledged that resin composites as presently used in the restoration of posterior teeth, despite many significant developments in recent times, are not ideal restorative materials. Further developments and refinements, for example to greatly reduce, if not eliminate, polymerisation shrinkage, are necessary. Composite shares some contraindications to placement - which in common with amalgam - include patients with poor compliance, poor oral hygiene and poor moisture control. ${ }^{10}$ In addition, composite has specific limitations when restoring cavities with subgingival margins. ${ }^{10}$ However, techniques exist to manage these situations and these will be facilitated by anticipated, highly desirable refinements and developments in composite systems that will occur at an ever-increasing rate in coming years.

\section{DISCONNECT}

In the UK there is, in the experience of the authors, an unfortunate disconnect of variable degree between the teaching and practice of operative dentistry in dental schools and primary dental care services, with dental schools tending to embrace the modern management of caries, the use of principally composites in the restoration of posterior teeth and minimally interventive dentistry to a greater extent than those engaged in primary dental care services. ${ }^{21}$ National and international surveys on the teaching of posterior composite restorations over the past 25 years have demonstrated a progressive increase in the teaching and clinical experience in the field of posterior composite restorations. ${ }^{22-35}$ In UK dental schools, undergraduate students have for a number of years gained, on average, more experience in the placement of posterior composite restorations than in the placement of dental amalgams (on average 55\% posterior composite:45\% amalgam), ${ }^{28}$ with much of the remaining use of dental amalgam being the replacement of dental amalgams in older patients belonging to the "heavy metal generation'. In contrast, surveys on aspects of general dental practice in the UK indicate that $59-75 \%$ of posterior restorations placed are of dental amalgam, ${ }^{3}$ with amalgam still being widely used contrary to best available evidence, in the initial management of lesions of caries, creating yet another generation of dental amalgam patients. The reasons for this worrisome disconnect are primarily related to dental schools wishing to teach according to best evidence and the realities of working in primary dental care services, tempered, it is suggested, by a reluctance among some established practitioners to adopt new approaches to their practice of operative dentistry.

\section{WISHFUL THINKING}

Setting aside any wishful thinking that one way or another mercury will continue to be available for widespread dental purposes after the implementation of the Minamata Treaty, the idea fostered by some that a new type of material will conveniently become available to 'save the day' must be questioned as unrealistic. Even if a new, ideal posterior restorative material was soon to be introduced, it would be many years before its efficacy and long-term viability could be established. Furthermore, assuming the need for new approaches and possibly novel instrumentation and devices to successfully apply the new ideal material, it could be two or 
more decades before the dental workforce was suitably equipped and competent to make the material work to the intended advantage in clinical practice. In other words, for at least a decade or so following the implementation of the Minamata Treaty the public is going to look to the dental profession to successfully apply existing types of tooth coloured restorative systems, notably composites, in ways to meet patients' needs and expectations. Existing materials will no doubt undergo further refinement and development in the next few years, but are unlikely to be made redundant by some innovation in dental biomaterials science. Bottom line: like it or not, composite will become the most widely used type of material in the restoration of posterior teeth until such times as some new form of superior, direct material has been developed, introduced, tried and tested and fully integrated into clinical practice. Accepting this situation, it is suggested that efforts in the immediate future should be focused on finding ways to make composites perform to their full potential rather than, as has more commonly been the case, attempting to identify some new limitation or potential weakness.

\section{QUESTIONS}

While it is hoped that further reductions in caries rates, future commissioning of NHS services and existing trends to extend the application of composite systems will facilitate the phasing down of the use of dental amalgam, it is suggested that there is a need for concerted action to address the educational aspects of the forthcoming fundamental change to the clinical practice of dentistry. Should recent and future entrants to dental school be taught anything other than amalgam repair and replacement techniques, given that the availability of mercury for dental purposes may be limited to a few years by the time existing first year students graduate? Who will fund and provide the CPD necessary to make all existing members of the dental workforce competent in modern approaches to the restoration of posterior teeth, ranging from the management of initial lesions of caries, which require operative intervention, to the management of badly broken down teeth that may well require large complex restorations of ceramic rather than composite? The future acceptability and affordability of gold and other metal alloys for dental purposes is another significant uncertainty. With a commitment to manage a 'phasedown' in the use of amalgam and the possibility that patient acceptance of dental amalgam may rapidly decline following the signing of the Minamata Treaty, it is suggested that decisions on the educational issues have to be made sooner rather than later, followed quickly thereafter by the development of a strategic plan to manage not just the educational issues, but all aspects of the phasing-down of the use of dental amalgam.

\section{DENTAL SCHOOLS}

A long running project led by the authors has demonstrated that the teaching of posterior composites is well established in dental school teaching, not only in the UK and Ireland, but in countries including the United States, Canada, Japan, Spain, Brazil and Iran. ${ }^{22-35}$ Teaching of posterior composites was generally limited up until the late 1990s, with dental school graduates of the time having little or no clinical experience in the placement of such restorations. ${ }^{33-35}$ However, surveys in the early years of the last decade and again in 2009/10 demonstrated a significant increase in student experience in posterior composite placement. ${ }^{22-30}$ This shift has been supported by consensus guidance from the British Association of Teachers of Conservative Dentistry, who recommended in 2007 that composite be considered the 'material of choice' for the restoration of posterior teeth affected by initial lesions of caries. ${ }^{36}$ Nowadays, students in UK and Ireland dental schools gain more experience in the placement of posterior composites than amalgam, with a strong emphasis on minimally interventive dentistry (55\% posterior composite:45\% amalgam). ${ }^{28}$ Furthermore, the first preclinical skills (formerly 'phantom head') experience in the restoration of posterior teeth for the majority of students is now posterior composite rather than amalgam. ${ }^{28}$ As such, the next generation of dentists and therapists to join the dental workforce will be more skilled and experienced in the application of composite systems and principles of minimally interventive dentistry than ever before. ${ }^{37}$ Intuitively, students who are trained to apply composite systems to best possible advantage are likely to be minimally invasive in their approach to cavity design. Such intuition and skill must be nurtured and developed in the future, rather than criticised and quashed. Dental foundation training presents an excellent opportunity for skills such as the placement of posterior composites, developed initially at dental school, to be consolidated and advanced. Young graduates must be given opportunity to help lead the way in affecting real change in the way caries and other damage to posterior teeth is managed in the future. More of the same old 'drill-and-fill' with the unnecessary sacrifice of sound tooth tissue will just add to the difficulty of the necessary transition to modern, preventatively orientated, patient-centred approaches to operative dentistry. In a similar way, teaching in paediatric dentistry is leading the way in avoiding a further future generation of amalgam patients: in most UK dental schools amalgam placement is no longer taught for child patients. This is to be applauded and should continue: any schools continuing to teach amalgam placement in children, particularly in newly-erupted permanent teeth, should consider discontinuing this teaching at their earliest possible convenience.

Should dental schools discontinue the teaching of dental amalgam placement to new enrolling dental students? The view of the authors is that the answer to this question is a resounding 'yes', with effect from no later than 2015. Rather, the time and resources presently being spent on teaching amalgam placement could be put to better use, including enhanced diagnosis and management of early caries (primary and secondary), the teaching of advanced skills in composite placement and decision-making in relation to the application of refurbishment and repair procedures to extend the longevity of restorations in clinical service. Existing and future students would also benefit from more instruction in the use of indirect ceramics systems in the restoration of teeth that are badly broken down, have suffered extensive wear or fracture, or are otherwise compromised in ways that may not be best managed by a direct restorative approach.

A more immediate challenge for dental schools, as indicated in the various surveys on the teaching of posterior composites, is the need to work towards common 
approaches to certain aspects of posterior composite placement technique. Areas of uncertainty include:

- Bonding versus basing: there is poor agreement between dental schools, within and between countries, on the management of operatively exposed dentine. ${ }^{28,29}$ Despite evidence to support the use of 'total etching' (and bonding) in promoting dentine repair ${ }^{38,39}$ and the avoidance of postoperative sensitivity ${ }^{40}$ surveys of trends in general practice indicate that the majority of practitioners continue to place a cement base, or at least a liner of a hard setting calcium hydroxide cement before restoration with a composite. ${ }^{4}$ The placement of a base, let alone a liner, does little, if anything to preserve pulp vitality in the management of a typical cavity and invariably compromises the restoration of the biomechanical properties of the restored tooth unit. ${ }^{41}$ As has always been taught, one of the worst things to do in operative dentistry is to deepen a cavity to accommodate a liner or base of cement

- Matrices and wedges: despite longstanding evidence to demonstrate inappropriate clinical outcomes associated with the use of light transmitting wedges and clear matrix systems in the placement of posterior composites, ${ }^{42}$ there is continued evidence that such techniques continue to be taught and used in student clinics. ${ }^{28,29}$ Considering the notorious difficulties of achieving good proximal contacts in posterior composites, teaching discredited techniques that add to the challenge does not improve matters. The evidence-base for the use of preformed, metallic 'shells', sectional matrices and associated retainers and wedges is strong and growing ${ }^{43,44}$

- Bevels on cavosurface margins: despite work dating back to the 1990s, which concluded that there is no need to place a bevel along cavosurface margins before the placement of a posterior composite restoration, confusion remains in relation to this subject. ${ }^{45}$ Placing a long low bevel along the cavosurface margins of posterior cavities finished with fine diamond burs, in the way taught to enhance the bonding and shade match of anterior composites, increases the risk of iatrogenic damage to occlusal enamel in finishing. Furthermore such bevels do little, if anything to enhance the performance of a posterior composite and when it comes to restoration refurbishment, repair or replacement results in unnecessary enlargement of the cavity. ${ }^{10}$ Bevelling the cavosurface margin in regions where there is reduced thickness of enamel (such as the cervical regions of a proximal box) can cause loss of already limited enamel (prisms) and reduction in bonding. ${ }^{46,47}$

\section{CONTINUING PROFESSIONAL DEVELOPMENT}

Many dentists and dental therapists engaged in clinical practice in the UK graduated from dental school at a time when there was no teaching on posterior composite restorations and according to the findings of surveys on trends in general dental practice, many practitioners would appear not to have acted on whatever CPD they may have had on state-of-the-art posterior composite placement. This raises important and worrying questions for the profession in terms of the safe and effective delivery of posterior composite treatments with the forthcoming phase-down in the use of dental amalgam, in particular given the extent of the further CPD required and the relatively limited number of individuals willing and suitably qualified to provide the necessary courses which, in the interests of patient safety, should include elements of resource intensive hands-on instruction. With the dental amalgam phase-down clock ticking, postgraduate dental deans and other providers of CPD should give consideration to significantly increasing the provision of courses on posterior composites, while practitioners not familiar with the use of composites in the restoration of posterior teeth should seek opportunity to obtain the necessary skills, knowledge and understanding. While there may not be a case for compulsory certification of competence (credentialing), as may be necessary with the translation of anticipated developments in biomedical sciences into clinical practice, duty of care to patients should be sufficient to stimulate dentists and therapists to 'get to grips' with the latest advances in operative dentistry in their personal development plans. The field of posterior composites is extensive and expanding at an ever-increasing rate that even experts in the area find challenging to keep pace with. A significant commitment in terms of resource and personnel will be required to seamlessly move from dental amalgam to composite as the predominant material in the restoration of posterior teeth. The sooner the process begins the better it will be for all concerned - a classic case of do not put off until tomorrow what can be achieved today.

\section{PATIENT EDUCATION}

While many patients may welcome the phase-down in the use of dental amalgam, particularly if it is achieved at least in part by the provision of fewer fillings, they too must play a part through a change in understanding of the processes involved in the successful treatment and subsequent care of diseased and damaged teeth. Teeth restored with composites may look much better than teeth restored with dental amalgam, but the natural appearance of composite restored teeth should not lull patients into a false sense of all has been put right by the use of the tooth coloured material. Patients need to be appropriately advised and educated in relation to their own responsibilities in terms of dietary choice, oral hygiene practice and ongoing dental attendance.

\section{CONCLUSION}

Faced with the imminent phase-down in the use of amalgam, the dental profession must be proactive in addressing the relevant educational challenges, both in dental schools and in relation to CPD. With the continuing requirement to manage and treat patients effectively and safely during and following the phase-down of dental amalgam, the necessary developments in undergraduate curricula and CPD provision should be instigated sooner rather than later. In the meantime, research on the use of composites in the restoration of posterior teeth should focus less on limitations and possible weaknesses in favour of more work on enhancing the initial quality and in turn performance of posterior composites in clinical service. 
1. United Nations Environment Programme. Minamata covention agreed by nations. UNEP, 2013. Online article available at http://www.unep.org/ newscentre/default.aspx?DocumentID=2702\&tArtic elD=9373 (accessed May 2013).

2. Hancocks S. A sense of place. Br Dent J 2013; 214: 91.

3. Brunton P A, Burke F J, Sharif M 0 et al. Contemporary dental practice in the UK in 2008 aspects of direct restorations, endodontics and bleaching. Br Dent J 2012; 212: 63-67.

4. Gilmour A S, Latif M, Addy L D, Lynch C D. Placement of posterior composite restorations in United Kingdom dental practices: techniques, problems, and attitudes. Int Dent J 2009; 59: 148-154.

5. Steele J S. An independent review of NHS dental services in England. London: Department of Health, 2009. Online article available at http://webarchive nationalarchives.gov.uk/20130107105354/http:// www.dh.gov.uk/en/Publicationsandstatistics/ Publications/PublicationsPolicyAndGuidance/ DH_101137 (accessed May 2013).

6. Manhart J, Chen H, Hamm G, Hickel R. Review of the clinical survival of direct and indirect restorations in posterior teeth of the permanent dentition. Oper Dent 2004; 29: 481-508.

7. Opdam N J, Bronkhurst E M, Roeters J M, Loomans $B$ A. A retrospective study clinical study on longevity of posterior composite and amalgam restorations. Dent Mater 2007; 23: 2-8.

8. Opdam N J, Bronkhorst E M, Loomans B A, Huysmans M C. 12-year survival of composite vs amalgam restorations. J Dent Res 2010; 89: 10631067.

9. Roeters J J, Shortall A C, Opdam N J. Can a single composite resin serve all purposes? Br Dent J 2005; 199: 73-79.

10. Lynch C D. Successful posterior composites. London: Quintessence Publishing Co., 2008.

11. Ritter A V. Posterior composites revisited. J Esthet Restor Dent 2008; 20: 57-67.

12. Wilson N H. Minimally invasive dentistry - the management of caries. London: Quintessence Publishing Co., 2007

13. Watts D C, El Mowafy O M, Grant A A. Fracture resistance of lower molars with class I composite and amalgam restorations. Dent Mater 1987; 3: $261-264$.

14. Blum I R, Lynch C D, Wilson N H. Teaching of direct composite restoration repair in undergraduate dental schools in the United Kingdom and Ireland. Eur J Dent Educ 2012; 16: e53-e58.

15. Lynch C D, Blum I R, Frazier K B, Haisch L, Wilson $\mathrm{N} \mathrm{H}$. Repair or replacement of defective direct composite restorations: contemporary teaching in US and Canadian dental schools. J Am Dent Assoc 2012; 143: 157-163.

16. Blum I R, Lynch C D, Wilson N H. Teaching of the repair of defective composite restorations in Scandinavian dental schools. J Oral Rehabil 2012: 39: $210-216$
17. Blum I R, Lynch C D, Schreiver A, Heidemann D, Wilson $\mathrm{N} \mathrm{H}$. Repair versus replacement of defective composite restorations in German dental schools. Eur J Prosthodont Restor Dent 2011; 19: 56-61.

18. Lynch C D, Hiyashi M, Seow L L, Blum I R, Wilson $\mathrm{N} \mathrm{H}$. The management of defective composite restorations: current trends in dental school teaching in Japan. Oper Dent 2013; epub ahead of print.

19. Opdam N J M, Bronkhorst E M, Loomans B A, Huysmans M C. Longevity of repaired restorations: a practice based study. J Dent 2012; 40: 829-835.

20. Shahdad S A, Kennedy J G. Bond strength of repaired anterior composite resin: an in vitro study. J Dent 1998; 26: 685-694.

21. Lynch C D, McConnell R J, Wilson N H. Challenges to teaching posterior composite resin restorations in the United Kingdom and Ireland. Br Dent J 2006 201: 747-750.

22. Lynch C D, McConnell R J, Wilson N H. The teaching of posterior composite resin restorations in undergraduate dental schools in Ireland and the United Kingdom. Eur J Dent Educ 2006; 10: 38-43.

23. Lynch C D, McConnell R J, Wilson N H. Teaching the placement of posterior resin-based composite restorations in US dental schools. J Am Dent Assoc 2006; 137: 619-625

24. Lynch C D, McConnell R J, Wilson N H. Teaching the use of resin composites in Canadian dental schools: how do current educational practices compare to North American trends? Journal of the Canadian Dental Association 2006; 72: 321.

25. Lynch C D, McConnell R J, Wilson N H. Trends in the placement of posterior composites in dental schools. J Dent Educ 2007; 71: 430-434.

26. Hiyashi M, Seow L L, Lynch C D, Wilson N H. Teaching of posterior composite restorations in Japanese Dental Schools. J Oral Rehabil 2009; 36: 292-298.

27. Sadeghi M, Lynch C D, Wilson N H. Trends in denta education in the East Mediterranean - an example from Iran: posterior composites and beyond. Eur J Prosthodont Restor Dent 2009; 17: 182-187.

28. Lynch C D, Frazier K B, McConnell R J, Blum I R, Wilson $\mathrm{N} \mathrm{H}$. State-of-the-art techniques in operative dentistry: contemporary teaching of posterior composites in UK and Irish dental schools. Br Dent J 2010; 209: 129-136

29. Lynch C D, Frazier K B, McConnell R J, Blum I R, Wilson $\mathrm{N} \mathrm{H}$. Minimally invasive management of dental caries: contemporary teaching of posterior resin composites in North American dental schools. J Am Dent Assoc 2011; 142: 612-620.

30. Oyagüe R C, Lynch C D, McConnell R J, Wilson N H. Teaching the placement of posterior resin-based composite restorations in Spanish dental schools. Medicina Oral Patologia Oral y Cirugia Bucal 2012; 17: e661-e668

31. Fukushima M, Iwaku M, Setcos J C, Wilson $\mathrm{N} \mathrm{H}$, Mjor I A. Teaching of posterior composite restorations in Japanese dental schools. Int Dent J 2000; 50: 407-411.
32. Gordan V V, Mjör I A, Veiga Filho L C, Ritter A V. Teaching of posterior resin-based composite restorations in Brazilian dental schools. Quintessence Int 2000; 31: 735-740.

33. Wilson N H, Setcos J C. The teaching of posterior composites: a worldwide survey. J Dent 1989; 17: S29-S33.

34. Mjör I, Wilson N H. Teaching of Class I, Class II direct composite resin restorations: results of a survey of dental schools. J Am Dent Assoc 1998; 129: 1415-1419.

35. Wilson N H F, Mjör I. The teaching of class I and class II direct composite restorations in European dental schools. J Dent 2000; 28: 15-21.

36. Lynch C D, Shortall A C, Stewardson D, Tomson PL Burke FJ. Teaching posterior composite resin restorations in the United Kingdom and Ireland: consensus views of teachers. Br Dent J 2007; 203: 183-187.

37. Lynch $C D$, Wilson $N$ H. Teaching of direct posterior resin composite restorations in UK dental therapy programmes. Br Dent J 2010; 208: 415-421.

38. Sadaghiani L, Gilmour A S, Lynch C D, Sloan A J. Effects of adhesive restorative agents on solubilising dentine matrix proteins. J Dent Res 2010; 89 (Special Issue B): abstract number 2957.

39. Sadaghiani L, Lynch C D, Sloan A J. Extracted dentine matrix proteins and dental pulp stem cell differentiation J Dent Res 2012: 91 (Special Issue C): abstract number 186 .

40. Burrow M F, Banomyong D, Harnirattisai C, Messer $\mathrm{H} \mathrm{H}$. Effect of glass-ionomer cement lining on postoperative sensitivity in occlusal cavities restored with resin composite - a randomized clinical trial. Oper Dent 2009; 34: 648-655

41. Opdam N J Bronkhorst E M, Roeters J M, Loomans $\mathrm{BA}$. Longevity and reasons for failure of sandwich and total-etch posterior composite resin restorations. J Adhes Dent 2007: 9: 469-475.

42. Müllejans R, Badawi M O, Raab W H, Lang H. An in vitro comparison of metal and transparent matrices used for bonded Class II resin composite restorations. Oper Dent 2003; 28: 122-126.

43. Loomans B A, Opdam N J, Roeters J F, Bronkhorst E M, Plasschaert A J. Influence of composite resin consistency and placement technique on proximal contact tightness of Class II restorations. J Adhes Dent 2006; 8: 305-310.

44. Loomans B A, Opdam N J, Roeters F J, Bronkhorst E M, Huysmans M C. Restoration techniques and marginal overhang in Class II composite resin restorations. J Dent 2009; 37: 712-717.

45. Isenberg B P. Leinfelder K F. Efficacy of beveling posterior composite resin preparations. J Esthet Dent 1990; 2: 70-73.

46. Lynch C D, O'Sullivan V R, Dockery P, McGillycuddy $C T$, Sloan A J. Hunter-Schreger Band patterns in human tooth enamel. J Anat 2010; 217: 106-115.

47. Lynch C D, O'Sullivan V R, Dockery P, McGillycuddy $C$ T, Rees J S, Sloan A J. Hunter-Schreger Band patterns and their implications for clinical dentistry. J Oral Rehabil 2011; 38: 359365 